\title{
EFEITO DA ADUBAÇÃO NA MANIFESTAÇÃO DA RESISTÊNCIA DE FEIJOEIRO AO ATAQUE DE CARUNCHO EM TESTES COM E SEM CHANCE DE ESCOLHA ${ }^{(1)}$
}

\author{
ARLINDO LEAL BOIÇA JÚNIOR ${ }^{(2)}$; ARACI MOLNAR ALONSO ${ }^{(3)}$
}

\begin{abstract}
RESUMO
Objetivando-se estudar a influência da adubação na manifestação da resistência de feijoeiro (Phaseolus vulgaris L.) (cultivares Rosinha G-2, ESAL-564 - Carioca e Diamante Negro) ao ataque de Acanthoscelides obtectus (Say, 1831) (Coleoptera: Bruchidae) foram conduzidos, na época das águas, testes com e sem chance de escolha, utilizando-se grãos obtidos de parcelas adubadas com N,P, K, NP, NK, PK, NPK, e sem adubo, totalizando 24 tratamentos. Os testes foram realizados em condições controladas de temperatura, umidade e luz. Foram avaliados o número de insetos atraídos e de ovos, em cada tratamento. Concluiu-se, no teste com chance de escolha, que o número de ovos de $A$. obtectus por recipiente foi reduzido pela aplicação do nitrogênio. A aplicação de nitrogênio em adubação resultou em menor porcentagem de insetos atraídos e menor número de ovos no genótipo Rosinha G-2. A manifestação da resistência nos genótipos ESAL-564 e Rosinha G-2 ao ataque de A. obtectus ficou evidente quando utilizados nitrogênio e potássio. Nos testes sem chance de escolha o consumo dos insetos foi reduzido nos grãos produzidos com a aplicação do nitrogênio. A aplicação de nitrogênio em adubação resultou no aumento do número de ovos de $A$. obtectus no genótipo ESAL-564. Não ficou evidente a manifestação da resistência nos genótipos ESAL-564 e Rosinha G-2 ao ataque do caruncho, pela aplicação dos macronutrientes N, P e K. Na ausência de fósforo o ciclo biológico do inseto foi maior na presença de potássio.

Palavras-chave: Phaseolus vulgaris, Insecta, Bruchidae, biologia, Acanthoscelides obtectus.
\end{abstract}

\section{ABSTRACT \\ EFFECT OF SOIL FERTILIZATION ON RESISTANCE EXPRESSION OF BEAN TO THE BEAN WEEVIL}

The objective of this study was to determine the influence of soil fertilizers on the resistance expression of bean (Phaseolus vulgaris L.) (cultivars Rosinha G-2, ESAL-564-Carioca and Diamante Negro), to Acanthoscelides obtectus (Say, 1831) (Coleoptera: Bruchidae). The grains for the tests were obtained from crop grown under different levels of N, P and K. The resistance tests were carried out under controlled conditions of temperature, light and relative humidity. It was observed the number of infested grains and the number of insect eggs in each treatment. The results of the free choice test showed that application of $\mathrm{N}$, reduced the number of eggs of $A$. obtectus, the percentage of attracted insects and the fecundity of $A$. obtectus reared on genotype Rosinha G-2. When $\mathrm{N}$ and $\mathrm{K}$ were applied, resistance expression to A. obtectus was more evident on the genotypes ESAL-564 and Rosinha G-2. In a no choice test, the results showed a reduction of grain consumption with an increase on the eggs number of A. obtectus on the genotype ESAL-564, with $\mathrm{N}$ application. The expression of the induced resistance by N, P and K application was not evident in the genotypes ESAL-564 and Rosinha G-2. When $\mathrm{P}$ was not used, the insect biological cycle became longer in the presence of $\mathrm{K}$.

Key words: Insecta, Bruchidae, biology, Acanthoscelides obtectus, Phaseolus vulgaris.

$\left({ }^{1}\right)$ Recebido para publicação em 3 de fevereiro de 1999 e aceito em 4 de janeiro de 2000.

( $\left.{ }^{2}\right)$ Departamento de Fitossanidade, FCAV/UNESP, Via de Acesso Prof. Paulo Donato Castellane, km 5, 14884-900 Jaboticabal (SP). E-mail: aboicaj@@fcav.unesp.br

(3) Pós-Graduanda do Curso de Mestrado em Entomologia Agrícola da FCAV/UNESP, Jaboticabal (SP). 


\section{INTRODUÇÃO}

Dentre os vários fatores que ocasionam perdas no potencial da cultura do feijoeiro, as pragas têm causado danos expressivos durante o ciclo de desenvolvimento da cultura e até mesmo após a colheita. Entre os diversos insetos-praga que afetam o feijão destaca-se o caruncho Acanthoscelides obtectus (Say, 1831) (Coleoptera: Bruchidae), considerado por RosSETTO (1966) um dos insetos mais prejudiciais aos grãos armazenados no Brasil. Celestino-FilHo e ALMEIDA (1980) estimaram perdas de $20 \%$ a $30 \%$ do total da produção de feijão no Brasil ocasionadas pelo ataque de insetos durante o armazenamento.

Dentre os controles de pragas do feijão armazenado o químico tem sido o mais utilizado. Entretanto, a pequena utilização de inseticidas registrados para aplicação direta em grãos de feijão, pelos usuários sem o devido conhecimento das técnicas de aplicação, tem ocasionado a incidência de resíduos tóxicos no produto e o controle insatisfatório das pragas, além de contribuir para o aumento da poluição ambiental e onerar os custos de armazenamento. Atualmente, com a maior valorização da qualidade dos produtos, torna-se necessário gerar novas alternativas de controle para possibilitar a implantação de técnicas com potencial de uso no futuro. Dentre essas medidas podem ser enfatizados a utilização de cultivares resistentes, a diversificação de cultivo, a época de semeadura, o uso de fertilizantes e o controle biológico.

Diferenças entre genótipos no campo, em relação a A. obtectus também foram observadas nos trabalhos realizados por MENTEN e MENTEN (1984), os quais verificaram que o genótipo Carioca e a linhagem mutante TMD-1 foram mais resistentes em relação aos genótipos Goiano Precoce e Rosinha G-2. Souza (1988) constatou, ainda, que estes últimos foram, em laboratório, altamente suscetíveis ao ataque de $A$. obtectus, em relação aos genótipos Regente, Tayhu, SP-7052, Carioca e Jalo, moderadamente suscetíveis, e Piratã-2 e Aroana, suscetíveis.

BASTIDAS et al. (1970) comentaram a respeito da necessidade de se desenvolverem estudos com a finalidade de agrupar os genótipos comerciais de feijoeiro, melhorados ou nativos, de acordo com a suscetibilidade ao ataque do caruncho. SCHOONHOVEN et al. (1983) encontraram em certos genótipos selvagens de feijoeiro elevado efeito de antibiose sobre A. obtectus. Osborn et al. (1986) verificaram que a proteína "arcelina" pode estar associada à resistência do feijão a bruquídeos, visto estar a mesma presente em genótipos selvagens resistentes e ausente em genótipos suscetíveis, cultivados e selvagens.
As causas da resistência do feijão às duas espécies de bruquídeos, Zabrotes subfasciatus e A. obtectus, são diferentes entre si. Alguns estudos revelaram que a "arcelina" foi, de fato, responsável pela resistência do feijão a Z. subfasciatus (CiAt, 1987; OsBorn et al., 1988). Por outro lado, GateHouse et al. (1987) concluíram que, pelo menos em parte, a causa da resistência no genótipo selvagem G 12953 a A. obtectus estava ligada a um heteropolissacarídeo. CARDONA et al. (1989), ao criarem A. obtectus e Z. subfasciatus em grãos artificiais de feijão, demonstraram que os fatores responsáveis pela resistência são de natureza química e estão presentes nos cotilédones.

A manifestação da resistência pode ser afetada por vários fatores ambientais incluindo algumas práticas culturais, como adubação e irrigação, e poderia ser melhor explorada no manejo de pragas (EMDEN, 1966; GALLO et al., 1988; LARA, 1991).

A aplicação de fertilizantes tem resultado, de modo geral, em um aumento do crescimento da planta e da fecundidade do inseto. A utilização de nitrogênio (N) freqüentemente induz a um aumento do número de espécies de insetos presentes no hospedeiro, ao passo que o efeito do fósforo (P) é menos evidente. Em muitos casos a adubação com potássio $(\mathrm{K})$ tem aumentado a manifestação da resistência. Ambos, P e $\mathrm{K}$, são requeridos, tanto pelo hospedeiro quanto pelo inseto que dele se alimenta, embora em quantidades menores que o nitrogênio, que é o elemento em maior quantidade na constituição das proteínas (JoNES, 1976).

$\mathrm{O}$ presente trabalho teve por objetivo avaliar $\mathrm{o}$ efeito da adubação à base de nitrogênio $(\mathrm{N})$, fósforo (P) e potássio (K), em suas diferentes combinações, na manifestação da resistência de três genótipos de feijoeiro semeados na "época das águas" ao ataque do caruncho A. obtectus, em testes de laboratório com e sem chance de escolha.

\section{MATERIAL E MÉTODOS}

\subsection{Produção de feijão em diferentes níveis de adubação}

Essa primeira etapa, baseando-se nos relatos de AlONso (1994), correspondeu à semeadura, no campo, de três genótipos de feijoeiro previamente selecionados: Rosinha G - 2 (menos adequado ao caruncho), Diamante Negro (intermediário) e ESAL-564 - Carioca (mais adequado). O objetivo foi obter as sementes para serem utilizadas nos testes conduzidos em laboratório.

$\mathrm{O}$ experimento foi desenvolvido em Latossolo Vermelho-Escuro - fase arenosa - e os resultados da análise química (0-20 $\mathrm{cm}$ de profundidade) foram os 
seguintes: $\mathrm{pH}\left(\mathrm{CaCl}_{2}\right)=5,2 ; \mathrm{P}$ (resina) $=17 \mathrm{mg} \cdot \mathrm{dm}^{-3}$; M.O. $\left(\mathrm{g} . \mathrm{dm}^{-3}\right)=20$; e em mmol.dm ${ }^{-3}: \mathrm{K}=2,4 ; \mathrm{Ca}=36$; $\mathrm{Mg}=6,0 ; \mathrm{H}+\mathrm{Al}=34,0 ; \mathrm{SB}=44,4 ; \mathrm{T}=78,4 ; \mathrm{V}=57 \%$.

Esses resultados indicaram a necessidade da aplicação de calcário. Após o preparo do solo e a aplicação de calcário dolomítico a área permaneceu em repouso cerca de 45 dias. A seguir, em uma área de $450 \mathrm{~m}^{2}$, efetuou-se a abertura dos sulcos de semeadura ocupados pelos oito tratamentos. Cada tratamento foi constituído por quatro parcelas distribuídas ao acaso. As parcelas foram compostas por cinco linhas medindo $4,5 \mathrm{~m}$ de comprimento, espaçadas de $0,6 \mathrm{~m}$. Na bordadura ( $1 .^{\text {a }}$ e $5 .^{\text {a }}$ linhas de cada parcela) foi semeado o genótipo EMGOPA-OURO. Assim, a área útil da parcela foi constituída pelas três linhas centrais, excluindo-se $0,5 \mathrm{~m}$ de cada extremidade.

Levando-se em consideração a análise química do solo e as recomendações de RAIJ et al. (1985), efetuouse a adubação mineral básica nos sulcos de semeadura, de forma manual. Os tratamentos foram constituídos pela aplicação de N, P e K, separadamente, e pelas combinações NP, NK, PK e NPK, além de uma testemunha sem adubação nos três genótipos de feijoeiro, totalizando 24 tratamentos. Aplicaram-se nutrientes correspondentes a 40-40-20 kg.ha ${ }^{-1}$ de N $\mathrm{P}_{2} \mathrm{O}_{5}-\mathrm{K}_{2} \mathrm{O}$, nas formas de sulfato de amônio, superfosfato simples e cloreto de potássio. O nitrogênio foi aplicado manualmente, em cobertura, aos 20 dias após a emergência das plantas.

A semeadura realizou-se em 14 de outubro de 1993, e o estande final foi de 12 a 15 plantas por metro linear. $\mathrm{O}$ controle das plantas daninhas efetuou-se através de capina manual, e o tratamento fitossanitário visando ao controle das principais pragas e doenças foi preventivo, a partir da segunda semana após a emergência das plantas.

Realizou-se a colheita manualmente, aos 80 dias após semeadura, e cada tratamento foi transportado em sacos de papel para secagem natural. Para os testes de laboratório cada tratamento foi constituído do material colhido e homogeneizado das quatro parcelas, e todos foram colocados em sacos de papel de $1,0 \mathrm{~kg}$ e acondicionados a $-10^{\circ} \mathrm{C}$ aproximadamente, durante dez dias, para eliminar eventuais infestações de campo por insetos. Após esse período o material permaneceu em estufa incubadora B.O.D. por cerca de uma semana, com a finalidade de uniformizar o teor de água no grão e entrar em equilíbrio higroscópico de $12,5 \%$.

\subsection{Teste de não-preferência}

Utilizando-se um conjunto composto por um disco de isopor branco com $44,0 \mathrm{~cm}$ de diâmetro e 2,5 cm de espessura e uma bandeja de plástico preto com 38,0 $\mathrm{cm}$ de diâmetro na base inferior, $44,0 \mathrm{~cm}$ de diâmetro na borda superior e $4,5 \mathrm{~cm}$ de altura, montou-se o teste com chance de escolha em forma de arena.

Os recipientes utilizados foram copinhos de plástico descartáveis $(50 \mathrm{~mL})$ cortados a uma altura de $2,5 \mathrm{~cm}$ da base, reduzindo, dessa forma, o volume de cada recipiente para $35 \mathrm{~mL}(3,5 \mathrm{~cm}$ de diâmetro na base, $2,5 \mathrm{~cm}$ de altura e $4,0 \mathrm{~cm}$ de diâmetro na borda superior).

No disco de isopor foi desenhado com caneta o contorno da circunferência da borda superior dos 24 recipientes $(4,0 \mathrm{~cm}$ de diâmetro) distribuídos de forma eqüidistante entre si e a $18,0 \mathrm{~cm}$ do centro do disco, em relação ao centro de cada circunferência. Foram retirados das 24 posições delimitadas no isopor discos de $3,8 \mathrm{~cm}$ de diâmetro, com o auxílio de um vazador aquecido, proporcionando, assim, o encaixe exato e ajustado de cada recipiente.

$\mathrm{Na}$ base inferior do disco de isopor foi acoplado, externamente um disco de papel (cartolina) de igual diâmetro, com o objetivo de proteger o fundo de todos os recipientes e do próprio disco. Após o encaixe dos recipientes no orifício em formato de disco, os 24 tratamentos foram distribuídos ao acaso, por sorteio.

Cada recipiente recebeu $10 \mathrm{~g}$ de feijão. A seguir foram liberados no centro da arena 96 insetos coletados, ao acaso, de uma colônia com 48 horas de idade. Imediatamente após a infestação a arena foi tampada com outra bandeja idêntica, invertida, e a lateral vedada com fita crepe. Esse conjunto foi levado para estufa incubadora B.O.D. modelo 347, regulada para fotofase de 12 horas, à temperatura de $27 \pm 2{ }^{\circ} \mathrm{C}$ e umidade relativa de $70 \pm 5 \%$. Após 48 horas todos os recipientes foram tampados, permanecendo nas condições controladas até o início da contagem dos ovos e dos insetos atraídos. Cada conjunto (disco-bandeja) correspondeu a uma repetição, e foram utilizadas dez repetições.

\subsection{Aspectos biológicos de A. obtectus em três genótipos de feijoeiro}

Inicialmente foi necessário estabelecer nos testes uma criação massal do inseto em grãos recém-colhidos, utilizando-se para isso o genótipo Aeté-3. A condução de todos os testes do experimento e a criação foram realizadas em estufa incubadora B.O.D. Para a realização dos testes as sementes foram colocadas em recipientes cilíndricos, de plástico transparente, de 4,0 cm de diâmetro e $4,0 \mathrm{~cm}$ de altura ( $50 \mathrm{~mL}$ ), com tampa. Cada recipiente recebeu $10 \mathrm{~g}$ de feijão de cada genótipo e quatro insetos com 48 horas de idade, coletados ao acaso. Utilizando-se oito repetições os 
recipientes foram tampados e conduzidos a B.O.D., assim permanecendo até o final da coleta dos dados.

As variáveis analisadas foram: número total de ovos por recipiente, porcentagem de insetos emergidos por recipiente, massa de grão consumido por inseto, longevidade de adultos (dias), massa de adulto com 96 horas de idade $(\mathrm{mg})$ e ciclo biológico de ovo a adulto (dias).

\subsection{Análises estatísticas}

O delineamento experimental utilizado em ambos os testes (com e sem chance de escolha) foi inteiramente casualizado, em um arranjo fatorial de 3x8 (3 genótipos e 8 tratamentos). Os dados obtidos foram submetidos à análise de variância pelo teste $\mathrm{F}$, e as médias comparadas pelo teste de Tukey (5\%).

\section{RESULTADOS E DISCUSSÃO}

\subsection{Teste de não-preferência}

A porcentagem de insetos por recipiente (Quadro 1) foi significativamente maior apenas nos tratamentos com a presença de $\mathrm{P}$.

As interações entre genótipos vs. nitrogênio e entre nitrogênio vs. potássio (Quadro 1) apresentaram diferenças significativas. Na presença de N ocorreram diferenças significativas entre os genótipos (Quadro 2), dado que 'ESAL-564' atraiu significativamente mais insetos que 'Rosinha G-2', concluindo-se, então, que a adubação com $\mathrm{N}$ aumentou a manifestação da não-preferência no genótipo Rosinha G-2.

Quanto ao efeito da adubação com $\mathrm{N}$ em cada genótipo, foram verificadas diferenças significativas somente no genótipo Rosinha G-2, o qual apresentou menor número de insetos na presença desse nutriente. No mesmo quadro (2) verifica-se que, para o desdobramento da interação $\mathrm{N}$ vs. $\mathrm{K}$ sobre a nãopreferência dos insetos, ocorreram diferenças significativas na ausência de $\mathrm{K}$, em que maior número de insetos foi observado no tratamento sem N. Por outro lado, nos tratamentos com K não foram observadas diferenças significativas, concluindo-se, assim, que a presença do mesmo interferiu na resposta dos insetos adultos à adubação nitrogenada.

Com relação ao número total de ovos por recipiente pode-se verificar que foram observadas diferenças significativas apenas na ausência e presença de $\mathrm{N}$ e de $\mathrm{P}$ e nas interações entre genótipos vs. $\mathrm{N}$, genótipo vs. $\mathrm{K}$ e $\mathrm{N}$ vs. K. Observa-se, ainda, que na ausência de $\mathrm{N}$ ocorreu maior número de ovos por recipiente; portanto, $\mathrm{N}$ acarretou menor oviposição do inseto em teste com chance de escolha. Com relação a P verfica-se o oposto, ou seja, o maior número
Quadro 1. Porcentagem de insetos atraídos e número total de ovos de Acanthoscelides obtectus por recipiente, obtidos em três genótipos de feijoeiro, em teste com chance de escolha (T: $27 \pm 2{ }^{\circ}$ C; U.R.: $70 \pm 5 \%$, fotofase: $12 \mathrm{~h}$ )

\begin{tabular}{|c|c|c|}
\hline Tratamentos & $\begin{array}{c}\text { Insetos } \\
\text { atraídos }^{(1)} \\
\% \\
\end{array}$ & $\begin{array}{c}\text { Total de } \\
\text { ovos }^{(2)} \\
n^{\circ}\end{array}$ \\
\hline ESAL-564 & 11,3 & 3,43 \\
\hline Rosinha G-2 & 10,2 & 3,13 \\
\hline Diamante Negro & 11,0 & 3,30 \\
\hline Teste F & $1,1^{\mathrm{ns}}$ & $0,9^{\mathrm{ns}}$ \\
\hline \multicolumn{3}{|l|}{ Nitrogênio (N) } \\
\hline Sem N & 11,3 & $3,4 a$ \\
\hline Com N & 10,4 & $3,1 \mathrm{~b}$ \\
\hline Teste F & $2,5^{\mathrm{ns}}$ & $4,0^{*}$ \\
\hline \multicolumn{3}{|l|}{ Fósforo (P) } \\
\hline Sem $P$ & $10,3 b$ & $3,1 b$ \\
\hline Com P & $11,4 a$ & $3,4 a$ \\
\hline Teste F & $4,0^{*}$ & $4,0^{*}$ \\
\hline \multicolumn{3}{|l|}{ Potássio (K) } \\
\hline Sem K & 11,0 & 3,2 \\
\hline Com K & 10,6 & 3,2 \\
\hline Teste F & $0,5^{\mathrm{ns}}$ & $0,1^{\mathrm{ns}}$ \\
\hline \multicolumn{3}{|l|}{ Teste F } \\
\hline Interação Genótipo x N & $5,2^{*}$ & $4,1^{*}$ \\
\hline Interação Genótipo x P & $1,2^{\text {ns }}$ & $2,6^{\mathrm{ns}}$ \\
\hline Interação Genótipo x K & $2,5^{\mathrm{ns}}$ & $3,4^{*}$ \\
\hline Interação Genótipo x P & $1,0^{\mathrm{ns}}$ & $2,5^{\mathrm{ns}}$ \\
\hline Interação N x K & $4,5^{*}$ & $6,9^{*}$ \\
\hline Interação P x K & $0,3^{\text {ns }}$ & $0,3 \mathrm{~ns}$ \\
\hline
\end{tabular}

${ }^{(1)}$ Os dados foram transformados em arc sen $\sqrt{\% / 100}$ para análise.

${ }^{(2)}$ Os dados foram transformados em $\log (x+1,0)$ para análise. Médias seguidas pela mesma letra não diferem significativamente entre si, pelo teste de Tukey ao nível de $5 \%$.

de ovos foi observado no tratamento com a presença deste elemento (Quadro 1).

Analisando-se o desdobramento da interação genótipo vs. $\mathrm{N}$, referente ao número total de ovos por recipiente (Quadro 3), observa-se que na presença desse elemento, 'ESAL-564', apesar de não diferir estatisticamente do genótipo Diamante Negro, apresentou número maior de ovos por recipiente, diferindo estatisticamente de 'Rosinha G-2'. Quanto à presença ou ausência de $\mathrm{N}$ dentro de cada genótipo testado foram verificadas diferenças significativas somente para o genótipo 'Rosinha G-2', o qual se apresentou menos atrativo para o inseto na presença 
de N. Pode-se observar ainda que não ocorreram diferenças significativas entre os genótipos na ausência de K, e em sua presença foram verificadas diferenças estatísticas: o genótipo ESAL-564 apresentou maior número de oviposições, não diferindo estatisticamente de 'Diamante Negro', mas diferindo de 'Rosinha G-2'. Para o efeito de K dentro dos genótipos, notam-se diferenças significativas somente para 'Rosinha G-2', o qual se comportou como menos atrativo para oviposição (na presença desse elemento).

Para a interação N vs. K pode-se observar que não houve diferença estatística para $\mathrm{N}$ na presença de $\mathrm{K}$ (Quadro 3). Na ausência deste, porém, a diferença estatística foi apontada no tratamento com $\mathrm{N}$, que apresentou menor número de oviposições do inseto.

Assim, no teste com chance de escolha não foram observadas diferenças estatísticas entre os genótipos, verificando-se, no entanto, diferenças quanto à ausência e presença de $\mathrm{N}, \mathrm{P}$ e $\mathrm{K}$ e de interações entre genótipos vs. N, genótipos vs. K e N vs. K (Quadros 1, 2 e 3). Em relação a $P$, sua ausência ou presença interferiu na porcentagem de insetos atraídos por recipiente e no número de ovos por recipiente (Quadro 1).

Para análise geral dos resultados pode-se comprovar em Herzog e FunderburK (1986) que as alterações nos níveis nutricionais de plantas podem influenciar os danos causados por insetos, pelo uso de fertilizantes. O efeito do fósforo $(\mathrm{P})$ e do potássio $(\mathrm{K})$ foi menos evidente em relação ao nitrogênio $(\mathrm{N})$, o que concorda com JonEs (1976). Porém em relação ao nitrogênio $(\mathrm{N})$, este experimento enquadra-se nas

Quadro 2. Valores da análise do desdobramento das interações entre genótipos de feijoeiro vs. nitrogênio $(\mathrm{N})$ e N vs. potássio (K), referentes à porcentagem de Acanthoscelides obtectus atraídos por recipiente, em teste com chance de escolha

\begin{tabular}{lccc}
\hline Genótipos & Sem N & Com N & Teste F \\
\hline ESAL 564 & 10,5 & $12,0 \mathrm{a}$ & $2,4^{\mathrm{ns}}$ \\
Rosinha G-2 & $11,7 \mathrm{~A}$ & $8,8 \mathrm{Bb}$ & $8,6^{*}$ \\
Diamante Negro & 11,7 & $10,3 \mathrm{ab}$ & $1,8^{\mathrm{ns}}$ \\
\hline Teste F & $0,9^{\mathrm{ns}}$ & $5,4^{*}$ & \\
Genótipos & Sem K & Com K & Teste F \\
Sem N & $12,1 \mathrm{a}$ & $10,5 \mathrm{~B}$ & $4,0^{*}$ \\
Com N & $10,0 \mathrm{~b}$ & 10,8 & $1,0^{\mathrm{ns}}$ \\
\hline Teste F & $6,9^{*}$ & $0,1^{\mathrm{ns}}$ & \\
\hline
\end{tabular}

Médias seguidas pela mesma letra, minúscula na coluna e maiúscula na linha, não diferem significativamente entre si pelo teste de Tukey ao nível de 5\%. Para a análise os dados foram transformados em arc sen $\sqrt{\% / 100}$. observações de SCRIBER (1984), que verificou que N interfere negativamente nos parâmetros populacionais dos insetos (em 25\% das pesquisas com este elemento), como também influencia o grau de aceitação da planta pelo inseto (McGinNIS e KASTING, 1966; Mattson, 1980), uma vez que o elemento $N$ interferiu negativamente na oviposição e atratividade de $A$. obtectus no genótipo Rosinha G-2, em relação a ESAL564 e Diamante Negro, em teste com chance de escolha.

Os poucos experimentos visando à avaliação de resistência de genótipos de feijoeiro em relação ao $A$. obtectus, encontrados na literatura colocam 'Rosinha G-2' como suscetível em testes com chance de escolha (Menten e Menten, 1984; Souza, 1988), discordando dos resultados obtidos na presente pesquisa. Isso pode ser devido aos genótipos usados por aqueles autores, diferentes dos empregados nesta pesquisa.

Diante dos resultados obtidos sugere-se que o genótipo Rosinha G-2 é o menos preferido para oviposição na presença ou ausência de alguns elementos químicos aplicados na adubação, possivelmente devido à ação de alguns compostos que induziram o material a ser menos infestado.

Por tal razão, verifica-se a necessidade de maiores pesquisas com essa espécie de bruquídeo frente aos diferentes genótipos existentes no mercado e nos

Quadro 3. Valores da análise do desdobramento das interações entre genótipos de feijoeiro vs. nitrogênio $(\mathrm{N})$, genótipos vs. potássio (K) e N vs. K, referentes ao número total de ovos de Acanthoscelides obtectus por recipiente, em teste com chance de escolha

\begin{tabular}{lccc}
\hline Genótipos & Sem N & Com N & Teste F \\
\hline ESAL-564 & 3,2 & $3,5 \mathrm{a}$ & $1,1^{\mathrm{ns}}$ \\
Rosinha G-2 & $3,5 \mathrm{~A}$ & $2,6 \mathrm{Bb}$ & $8,8^{*}$ \\
Diamante Negro & 3,5 & $3,0 \mathrm{ab}$ & $2,4^{\mathrm{ns}}$ \\
\hline Teste F & $0,6^{\mathrm{ns}}$ & $4,5^{*}$ & \\
Genótipos & Sem K & Com K & Teste F \\
ESAL-564 & 3,2 & $3,6 \mathrm{a}$ & $1,4^{\mathrm{ns}}$ \\
Rosinha G-2 & $3,4 \mathrm{~A}$ & $2,7 \mathrm{Bb}$ & $4,8^{*}$ \\
Diamante Negro & 3,1 & $3,4 \mathrm{ab}$ & $0,6^{\mathrm{ns}}$ \\
\hline Teste F & $0,4^{\mathrm{ns}}$ & $3,9^{*}$ & \\
\hline Tratamentos & Sem K & Com K & Teste F \\
Sem N & $3,7 \mathrm{a}$ & 3,2 & $3,7^{\mathrm{ns}}$ \\
Com N & $2,8 \mathrm{~b}$ & 3,3 & $3,1^{\mathrm{ns}}$ \\
\hline Teste F & $10,7^{*}$ & $0,1^{\mathrm{ns}}$ & \\
\hline
\end{tabular}

* Médias seguidas pela mesma letra não diferem significativamente entre si pelo teste de Tukey ao nível de $5 \%$. Os dados foram transformados em $\log (x+1,0)$ para análise. 
bancos de germoplasma, para gerar mais informações quanto à biologia, comportamento e, principalmente, respostas aos fertilizantes, além das exigências nutricionais do inseto.

\subsection{Aspectos biológicos de A. obtectus em três genótipos de feijoeiro}

Quanto ao número total de ovos por recipiente (Quadro 4) os dados mostram diferenças significativas apenas para a interação genótipos vs. N. Assim, considerando o desdobramento, pode-se observar pelo quadro 5 que não houve diferença entre os genótipos com a presença de $\mathrm{N}$, mas que, na sua ausência foram observadas diferenças, dado que o maior número de ovos foi obtido em 'Diamante Negro' e o menor em 'ESAL-564'. Analisando-se o efeito da presença e ausência de $\mathrm{N}$ em cada genótipo constata-se que a ausência de $\mathrm{N}$ afetou negativamente a oviposição somente para o ESAL - 564.

Pela análise dos dados relativos à porcentagem de insetos emergidos por recipiente observa-se pelo quadro 4 que houve diferenças significativas somente entre os genótipos. A maior porcentagem de insetos emergidos foi observada em 'ESAL-564' seguido por 'Diamante Negro', os quais não diferiram entre si mas diferiram estatisticamente de 'Rosinha G-2', apresentando este a menor porcentagem de insetos emergidos por recipiente, confirmando, dessa forma, certo grau de resistência em relação a esses dois genótipos. Esse resultado discorda de Menten e Menten (1984) que apontaram 'Rosinha G-2' como suscetível em comparação aos genótipos Carioca e TMD-1.

Quanto à massa de grão consumido por inseto (mg) pode-se observar pelo quadro 4 que a análise estatística apontou significância apenas para os tratamentos com e sem $\mathrm{N}$. Na ausência de $\mathrm{N}$ houve maior consumo, concluindo-se, portanto, que a presença de $\mathrm{N}$ afetou negativamente a massa de grão consumido por inseto.

No que se refere à longevidade de adulto (dias) foram verificadas diferenças significativas somente entre os genótipos (Quadro 4) com a maior longevidade de adulto, observada em 'ESAL-564', que diferiu significativamente dos outros dois. Portanto, os insetos que se alimentaram durante a fase imatura com esse genótipo tiveram adultos mais longevos (28,5 dias), comparados aos genótipos Rosinha G-2 (23,7 dias) e Diamante Negro (24,2 dias).

Pode-se observar através do quadro 6 que não foram verificadas diferenças significativas entre os dados de massa de inseto adulto, em relação aos três genótipos, e a ausência e presença de N, P e K.

Quanto ao efeito dos genótipos no ciclo biológico dos insetos emergidos verifica-se que em ‘Diamante
Quadro 4. Número total de ovos por recipiente (NO), porcentagem de insetos emergidos por recipiente (NE), massa de grão consumido por inseto (MG), longevidade de adulto (LA) de Acanthoscelides obtectus, obtidos em três genótipos de feijoeiro, em teste sem chance de escolha (T: $27 \pm 2{ }^{\circ} \mathrm{C}$; U.R.: $70 \pm 5 \%$; fotofase: 12 horas)

\begin{tabular}{|c|c|c|c|c|}
\hline Tratamentos & $\mathrm{NO}^{(1)}$ & $\mathrm{NE}^{(2)}$ & $\mathrm{MG}^{(3)}$ & $\mathrm{LA}^{(3)}$ \\
\hline & & & $\mathrm{mg}$ & dias \\
\hline ESAL-564 & 3,5 & $77,7 \mathrm{a}$ & 13,5 & $28,5 \mathrm{a}$ \\
\hline Rosinha G-2 & 3,5 & $68,7 \mathrm{~b}$ & 13,9 & $23,7 \mathrm{~b}$ \\
\hline Diamante Negro & 3,7 & $75,8 \mathrm{a}$ & 12,9 & $24,2 b$ \\
\hline Teste F & $3,0^{\mathrm{ns}}$ & $12,2^{*}$ & $1,1^{\mathrm{ns}}$ & $8,2^{*}$ \\
\hline \multicolumn{5}{|l|}{ Nitrogênio (N) } \\
\hline Sem N & 3,6 & 74,1 & $14,0 \mathrm{a}$ & 26,3 \\
\hline Com N & 3,6 & 74,0 & $12,9 b$ & 24,7 \\
\hline Teste F & $0,1^{\text {ns }}$ & $0,1^{\text {ns }}$ & $4,6^{*}$ & $2,2^{\mathrm{n}}$ \\
\hline \multicolumn{5}{|l|}{ Fósforo $(\mathrm{P})$} \\
\hline Sem $P$ & 3,5 & 74,4 & 13,5 & 26,1 \\
\hline Com P & 3,6 & 73,7 & 13,4 & 24,9 \\
\hline Teste F & $0,3^{\text {ns }}$ & $0,1^{\mathrm{ns}}$ & $0,0^{\mathrm{ns}}$ & $1,2^{\mathrm{ns}}$ \\
\hline \multicolumn{5}{|l|}{ Potássio (K) } \\
\hline Sem K & 3,6 & 75,3 & 13,8 & 26,4 \\
\hline Com K & 3,6 & 72,8 & 13,1 & 24,6 \\
\hline Teste F & $0,1^{\mathrm{ns}}$ & $2,5^{\mathrm{ns}}$ & $2,0^{\mathrm{ns}}$ & $2,7^{\mathrm{ns}}$ \\
\hline \multicolumn{5}{|l|}{ Teste F } \\
\hline Interação Genótipo x N & $3,6^{*}$ & $0,1^{\mathrm{ns}}$ & $1,8^{\mathrm{ns}}$ & $1,0^{\mathrm{ns}}$ \\
\hline Interação Genótipo x P & $0,8^{\text {ns }}$ & $0,6^{\mathrm{ns}}$ & $2,8^{\mathrm{ns}}$ & $0,3^{\mathrm{ns}}$ \\
\hline Interação Genótipo x K & $0,2^{\text {ns }}$ & $0,1^{\mathrm{ns}}$ & $2,0^{\mathrm{ns}}$ & $0,6^{\mathrm{ns}}$ \\
\hline Interação N X P & $2,8^{\text {ns }}$ & $3,8^{\text {ns }}$ & $0,2^{\mathrm{ns}}$ & $0,9^{\mathrm{ns}}$ \\
\hline Interação N X K & $0,2^{\text {ns }}$ & $0,8^{\text {ns }}$ & $0,1^{\mathrm{ns}}$ & $0,3^{\mathrm{ns}}$ \\
\hline Interação P X K & $0,1^{\mathrm{ns}}$ & $1,0^{\mathrm{ns}}$ & $0,1^{\mathrm{ns}}$ & $0,3^{\mathrm{ns}}$ \\
\hline
\end{tabular}

(1) Os dados foram transformados em $\log (x+1,0)$ para análise.

(2) Os dados foram transformados em arc sen $\sqrt{\% / 100}$ para análise.

(3) Os dados não foram transformados para análise.

* Médias seguidas pela mesma letra não diferem significativamente entre si pelo teste de Tukey ao nível de 5\%.

Negro' o ciclo foi maior (42,8 dias) e diferiu estatisticamente dos ciclos observados nos genótipos Rosinha G-2 (42,2 dias) e ESAL-564 (41,8 dias), que não diferiram significativamente entre si.

O ciclo também foi afetado pela ausência e presença de $K$, sendo estatisticamente menor na ausência deste elemento (Quadro 6).

Analisando-se os desdobramentos das interações referentes ao ciclo biológico (Quadro 7), nota-se que houve diferenças estatísticas entre os três genótipos apenas na presença de $\mathrm{P}$, com o maior ciclo para 
Quadro 5. Valores da análise do desdobramento da interação entre genótipos de feijoeiro vs. nitrogênio $(\mathrm{N})$ referente ao número total de ovos de Acanthoscelides obtectus por recipiente, em teste sem chance de escolha

\begin{tabular}{lccc}
\hline Genótipos & Sem N & Com N & Teste F \\
\hline ESAL-564 & $3,4 \mathrm{Bb}$ & $3,6 \mathrm{~A}$ & $5,6^{*}$ \\
Rosinha G-2 & $3,6 \mathrm{ab}$ & 3,5 & $1,0^{\mathrm{ns}}$ \\
Diamante Negro & $3,7 \mathrm{a}$ & 3,6 & $0,7^{\mathrm{ns}}$ \\
Teste F & $5,0^{*}$ & $1,6^{\mathrm{ns}}$ & \\
\hline
\end{tabular}

* Médias seguidas pela mesma letra, minúscula na coluna e maiúscula na linha, não diferem significativamente entre si pelo teste de Tukey ao nível de $5 \%$. Os dados foram transformados em $\log (x+1,0)$ para análise.

Quadro 6. Peso de inseto adulto (PI), ciclos biológicos de ovo a adulto (CB) e massa total de grãos consumidos (MTC) por Acanthoscelides obtectus, obtidos em três genótipos de feijoeiro em teste sem chance de escolha (T: $27 \pm 2{ }^{\circ} \mathrm{C}$; U.R.: 70 $\pm 5 \%$; fotofase: $12 \mathrm{~h}$ )

\begin{tabular}{|c|c|c|c|}
\hline Tratamentos & $\mathrm{PI}^{(1)}$ & $\mathrm{CB}^{(1)}$ & $\operatorname{MTC}^{(1)}$ \\
\hline & $\mathrm{mg}$ & dias & $\mathrm{mg}$ \\
\hline ESAL-564 & 3,4 & $41,8 b$ & $435,6 a b$ \\
\hline Rosinha G-2 & 3,2 & $42,2 b$ & $422,3 b$ \\
\hline Diamante Negro & 3,3 & $42,8 \mathrm{a}$ & $506,1 \mathrm{a}$ \\
\hline Teste F & $2,0^{\mathrm{ns}}$ & $12,2^{*}$ & $3,4^{*}$ \\
\hline \multicolumn{4}{|l|}{ Nitrogênio (N) } \\
\hline Sem N & 3,3 & 42,2 & 455,6 \\
\hline Com N & 3,3 & 42,3 & 453,7 \\
\hline Teste F & $0,1^{\mathrm{ns}}$ & $1,1^{\mathrm{ns}}$ & $0,1^{\mathrm{ns}}$ \\
\hline \multicolumn{4}{|l|}{ Fósforo (P) } \\
\hline Sem $P$ & 3,3 & 42,2 & 461,3 \\
\hline Com P & 3,3 & 42,3 & 448,0 \\
\hline Teste F & $0,1^{\text {ns }}$ & $0,5^{\mathrm{ns}}$ & $0,2^{\mathrm{ns}}$ \\
\hline \multicolumn{4}{|l|}{ Potássio (K) } \\
\hline Sem K & 3,3 & $42,0 \mathrm{~b}$ & 464,4 \\
\hline Com K & 3,3 & $42,5 \mathrm{a}$ & 444,9 \\
\hline Teste F & $1,5^{\mathrm{ns}}$ & $10,0^{*}$ & $0,4^{\mathrm{ns}}$ \\
\hline Interação Genótipo x N & $0,2^{\text {ns }}$ & $2,5^{\mathrm{ns}}$ & $2,8^{\mathrm{ns}}$ \\
\hline Interação Genótipo x P & $0,2^{\mathrm{ns}}$ & $3,0^{*}$ & $0,3^{\mathrm{ns}}$ \\
\hline Interação Genótipo x K & $0,5^{\mathrm{ns}}$ & $4,7^{*}$ & $0,9^{\text {ns }}$ \\
\hline Interação N x P & $0,1^{\mathrm{ns}}$ & $0,5^{\mathrm{ns}}$ & $0,1^{\mathrm{ns}}$ \\
\hline Interação N x K & $0,1^{\mathrm{ns}}$ & $0,6^{\mathrm{ns}}$ & $0,1^{\mathrm{ns}}$ \\
\hline Interação P x K & $0,6^{\mathrm{ns}}$ & $13,9 *$ & $0,1^{\mathrm{ns}}$ \\
\hline
\end{tabular}

* Médias seguidas pela mesma letra não diferem significativamente entre si pelo teste de Tukey ao nível de 5\%.

${ }^{(1)}$ Os dados não foram transformados para análise.
'Diamante Negro' (43,0 dias), o qual diferiu significativamente do valor observado no genótipo ESAL-564 (41,6 dias), tendo este o menor valor em relação aos outros tratamentos.

Para o efeito da presença e ausência de $P$ dentro de cada genótipo verifica-se que não ocorreram diferenças significativas, evidenciando a não influência desse elemento na manifestação da resistência, em teste sem chance de escolha.

Para a interação genótipo vs. K (Quadro 7) na ausência deste elemento, os maiores ciclos foram observados nos genótipos Diamante Negro e Rosinha G-2, os quais não diferiram significativamente entre si, diferindo, no entanto, do genótipo ESAL-564, sendo neste observado o menor ciclo do inseto. Na presença de K, 'Rosinha G-2' proporcionou o menor ciclo para o inseto e 'Diamante Negro' o maior, ambos não diferindo de 'ESAL-564'. Pela análise do efeito de K dentro dos genótipos verificam-se diferenças estatísticas significativas apenas para o genótipo ESAL564, no qual a ausência do elemento proporcionou uma redução no ciclo biológico de $A$. obtectus, sugerindo que K pode atuar na manifestação da resistência a essa praga.

Pelo mesmo quadro podem-se verificar diferenças estatísticas significativas, pois, quando não se aplicou $\mathrm{K}$, o ciclo foi maior com a presença de $\mathrm{P}$, e vice-versa. Por sua vez, na presença de $\mathrm{K}$ foi observado o menor ciclo quando se aplicou fósforo. Analisando-se o efeito de $\mathrm{K}$ dentro de $\mathrm{P}$ verificam-se diferenças estatísticas significativas apenas na ausência de $\mathrm{P}$, sendo o ciclo prolongado pela presença de K. Portanto, tanto $\mathrm{K}$ quanto $\mathrm{P}$, separadamente, prolongam o ciclo de $A$. obtectus; a combinação de ambos, porém, reduz o ciclo. $\mathrm{O}$ aumento deste é mais evidente pela presença de K e na ausência de $P$, sugerindo a influência desses nutrientes no ciclo biológico do inseto.

Com respeito à massa total de grão consumido (MTC) verificam-se diferenças significativas apenas entre os genótipos (Quadro 6) nos quais 'Diamante Negro' foi significativamente mais consumido que 'Rosinha G-2', o que sugere que este cultivar possa apresentar certo grau de resistência. Para essa variável, 'ESAL-564' situou-se como intermediário.

Em análise geral dos genótipos o 'ESAL-564' destacou-se por apresentar a maior porcentagem de insetos emergidos e a maior longevidade de adulto, ao passo que 'Rosinha G-2' apresentou os menores valores para esses dois parâmetros (Quadro 4). Por sua vez, 'Diamante Negro' posicionou-se como intermediário. Entretanto, a longevidade de adulto neste caso, não é ainda um parâmetro suficientemente seguro para diferenciar os genótipos quanto aos graus de resistência, nesta pesquisa. 
Quadro 7. Valores das análises do desdobramento das interações entre genótipos de feijoeiro vs. fósforo (P) e potássio (K) e entre fósforo vs. potássio referentes ao ciclo biológico (dias) de Acanthoscelides obtectus, em teste sem chance de escolha.

\begin{tabular}{lcccccc}
\hline Genótipos & Sem P & Com P & Teste F & Sem K & Com K & Teste F \\
\hline ESAL 564 & 42,0 & $41,6 \mathrm{c}$ & $2,4^{\mathrm{ns}}$ & $41,2 \mathrm{Bb}$ & $42,4 \mathrm{Aab}$ & $17,5^{*}$ \\
Rosinha G-2 & 42,0 & $42,3 \mathrm{~b}$ & $1,1^{\mathrm{ns}}$ & $42,2 \mathrm{a}$ & $42,1 \mathrm{~b}$ & $0,1^{\mathrm{ns}}$ \\
D. Negro & 42,5 & $43,0 \mathrm{a}$ & $3,1^{\mathrm{ns}}$ & $42,6 \mathrm{a}$ & $43,0 \mathrm{a}$ & $2,1^{\mathrm{ns}}$ \\
\hline Teste F & $2,2^{\mathrm{ns}}$ & $13,1^{*}$ & --- & $12,3^{*}$ & $4,7^{*}$ \\
\hline & Tratamentos & Sem K & Com K & Teste F & \\
\hline & Sem P & $41,6 \mathrm{Bb}$ & $42,7 \mathrm{Aa}$ & $23,8^{*}$ & \\
& Com P & $42,3 \mathrm{a}$ & $42,3 \mathrm{~b}$ & $0,1^{\mathrm{ns}}$ & \\
\hline
\end{tabular}

Médias seguidas pela mesma letra, minúscula na coluna e maiúscula na linha, não diferem significativamente entre si, pelo teste de Tukey ao nível de 5\% de probabilidade. Para a análise os dados não foram transformados.

Em 'Diamante Negro' constataram-se os maiores ciclos para A. obtectus, bem como a massa total de grão consumido (Quadro 6). No entanto, este último parâmetro está relacionado à massa de grão consumida por inseto, para os quais não foram constatadas diferenças significativas entre os três genótipos (Quadro 6).

Quanto à longevidade de adulto, os insetos que se alimentaram durante a fase imatura em 'Rosinha G-2' morreram mais cedo (Quadro 4). Assim, o parâmetro que melhor evidencia certo grau de resistência para 'Rosinha G-2', tendendo a ser do tipo não-preferência para alimentação e/ou antibiose, foi a porcentagem de insetos emergidos, principalmente em relação a 'ESAL-564', sendo este o mais suscetível.

\section{CONCLUSÕES}

\subsection{Teste com chance de escolha}

O número de ovos por recipiente de $A$. obtectus foi reduzido pela aplicação do nitrogênio; a qual, em adubação, resultou em menor porcentagem de insetos atraídos e menor número de ovos no genótipo Rosinha G-2. A manifestação da resistência nos genótipos ESAL-564 e Rosinha G-2 ao ataque de $A$. obtectus, pela aplicação dos macronutrientes (N, P e K) em adubação, foi mais evidente quando foram utilizados nitrogênio e potássio.

\subsection{Testes sem chance de escolha}

A massa de grão consumido por inseto foi reduzida pela aplicação do nitrogênio; a aplicação de nitrogênio em adubação resultou no aumento do número de ovos de $A$. obtectus no genótipo ESAL-564; a manifestação da resistência nos genótipos ESAL-564 e Rosinha G-2 ao ataque de $A$. obtectus, pela aplicação dos macronutrientes (N, P e K) em adubação, não foi evidente; e, na ausência de fósforo, o ciclo biológico do inseto foi maior na presença de potássio.

\section{REFERÊNCIAS BIBLIOGRÁFICAS}

ALONSO, A.M. Efeito da adubação na manifestação da resistência de feijoeiro (Phaseolus vulgaris L.) ao caruncho Acanthoscelides obtectus (Say, 1831) (Coleoptera: Bruchidae). Jaboticabal, 1994. 121p. Dissertação (Mestrado em Agronomia) -FCAV/UNESP, 1994.

BASTIDAS, C.R.; SANCHES, F.H.; BRAVO, G.V. Resistência de 5 variedades de frijol almacenado al ataque del gorgojo mayor (Acanthoscelides obtectus, Say). Fitotecnia Latinoamericana, Mexico, v.5, n.1, p.36-39, 1970.

CARDONA, C.; PASSOS, C.E.; KORNEGAY, J.; VALOR, J.; SERRANO, M. Antibiosis effects of wild dry bean accessions on the mexican bean weevil and the bean weevil (Coleoptera: Bruchidae). Journal of Economic Entomology, Lanhan, v.82, n.1, p.310-315, 1989.

CELESTINO FILHO, P.; ALMEIDA, A.A. Efeitos de infestação do Acanthoscelides obtectus (Say, 1831) com diferentes níveis, em feijão armazenado. In: CONGRESSO BRASILEIRO DE ENTOMOLOGIA, 6., Campinas, 1980. Resumos. Campinas: Sociedade Entomológica do Brasil, 1980. p.29.

CIAT. Centro Internacional de Agricultura Tropical. Hojas de Frijol. Boletín informativo del Programa de Frijol del CIAT, Colombia ,v.9, n.2, p.1-11, 1987.

EMDEN, VAN H.F. Studies on the relations of insect and host plants. III: A comparison of the reproduction of Brevicoryne brassicae and Mysus persicae (Hemiptera: Aphididae) on Brussels sprout plants supplied with different rates of nitrogen and potassium. Experimentalis et Applicate, v.9, p.444-460, 1966.

GALLO, D.; NAKANO, O.; SILVEIRA-NETO, S.; CARVALHO, R.P.L.; BATISTA, G.C.; BERTI FILHO, E.; PARRA, J.R.P.; ZUCCHI, R.A.; ALVES, S.B.; 
VENDRAMIM, J.D. Manual de entomologia agrícola. São Paulo : Agronômica Ceres, 1988. 648p.

GATEHOUSE, A.M.R.; DOBIE, P.; HODGES, R.J.; MEIK, J.; PUSZTAI, A.; BOULTER, D. Role of carbohydrates in insect resistance in Phaseolus vulgaris. Journal of Insect Physiology, Oxford, v.33, n.11, p.843-850, 1987.

HERZOG, D.C.; FUNDERBURK, J.E. Ecological bases for habitat management. In: KOGAN, M., (Ed.). Ecological theory and integrated pest management practice. New York : J. Wiley \& Sons, 1986. p.217-250.

JONES, F.G.W. Pest, resistance and fertilizers: fertilizer use and plant health. In: COLL INTERNATIONAL POTASH INSTITUTE, 12., 1976, Bern. Proceedings. Bern, 1976.

LARA, F.M. Princípios de resistência de plantas a insetos. 2.ed. São Paulo : Icone, 1991, 336p.

MATTSON, W.J. Herbivory in relation to plant nitrogen content. Annual Review Ecology and Systematics, Palo Alto, v.11, p.119-161, 1980.

McGINNIS, A.J.; KASTING, R. Comparison of tissues from solid and hollow-stemmed spring wheats during growth. IV. Apparent dry matter utilization and nitrogen balance in the two-striped grasshopper, Melanophus bivittatus. Journal of Insect Physiology, Oxford, v.12, p.671-678, 1966.

MENTEN, L.A.; MENTEN, J.O.M. Época de ataque de Acanthoscelides obtectus (Say) ao feijoeiro (Phaseolus vulgaris L.) sob condições de campo. Turrialba, San Jose, v.34, p.333-336, 1984.
OSBORN, T.C.; BLAKE, T.; GEPTS, P.; BLISS, F.A. Bean arcelin 2. Genetic variation, inheritance and linkage relationships of a novel seed protein of Phaseolus vulgaris L. Theoretical and Applied Genetics, Berlin, v.71, p.847-855, 1986.

OSBORN, T.C.; ALEXANDER, D.C.; SUN, S.S.M.; CARDONA, C.; BLISS, F.A. Insecticides activity and lecitin homology of arcelin seed protein. Science, Washington. v.240, p.207-210, 1988.

RAIJ, B. van; SILVA, N.M. da; BATAGLIA, O.C.; QUAGGIO, J.A.; HIROCE, R.; CANTARELLA, H.; BELLINAZZI JUNIOR, D.; DECHEN, A.R.; TRANI, P.E. Recomendação de Adubação e Calagem para o Estado de São Paulo. Campinas, Instituto Agronômico, 1985. 107p. (Boletim Técnico, 100)

ROSSETTO, C.J. Sugestões para o armazenamento de grãos no Brasil. O Agronômico, Campinas, v.18:38-51, 1966.

SCHOONHOVEN, A.V.; CARDONA, C.; VALOR, J. Low levels of resistance to the mexican bean weevil (Coleoptera: Bruchidae) in non-cultivated common bean accession. Journal of Economic Entomology, Lanham, v.75, p.567-569, 1983.

SCRIBER, J.M. Host plant suitability. In: BELL, W.; CARDE, R., (Eds.). Chemical ecology of insects. London : Chapman and Hall, 1984. p.159-202.

SOUZA, L.A. de. Resistência de dez genótipos de feijão ao Acanthoscelides obtectus em laboratório. Pesquisa Agropecuária Brasileira, Brasília, v.23, p.15-18, 1988. 